\title{
Comparison of clonidine and dexmedetomidin influence on the main indicators of hemodynamic during induction of anesthesia in neurooncological patients
}

\author{
R Nazarov ${ }^{1 *}$, A Kondratiev $^{2}$, M Rumiantseva ${ }^{2}$, A Petrova $^{2}$ \\ From ESICM LIVES 2015 \\ Berlin, Germany. 3-7 October 2015
}

\section{Introduction}

opioid and adrenergic antinociceptive systems are the components of neuroregulatory system of a brain stem. The impact on neuroregulatory systems is a point of theoretical and practical interest for neuroanesthesia. We successfully apply the method of anesthesia, which includes combined impact on opioid (fentanyl) and adrenergic (clonidine) antinociceptive systems. This method of anesthesia creates conditions for neurovegetative stability which are optimal for brain surgery.

Emergence of a more selective alfa2-adrenoagonist (Dexmedetomidin), allows to consider it as choice option for neurovegetative stabilization.

\section{Objectives}

To compare effects of Clonidine and Dexmedetomidin on the main indicators of hemodynamic during induction of anesthesia in neurosurgery.

\section{Methods}

In the research we included 63 patients who underwent operations on posterior brain fossa and pineal area. At all patients the aneshtesiological maintenance included: miorelaxant (pipekuronium $0,1 \mathrm{mg} / \mathrm{kg}$ or rokuronium $0,6 \mathrm{mg} / \mathrm{kg}$ ), hypnotic (propofol $2 \mathrm{mg} / \mathrm{kg}$ ), opioid analgetic (fentanyl of 3,54-5,88 mkg/ $\mathrm{kg}$ ) + alfa2-adrenoagonist (clonidine and dexmedetomidin). All the patients were divided into two groups: in the 1-st group (21 patient)

'Federal State Institution 'North-West Federal Research Center' of the Russian Ministry of Health, Anesthesiology and Intensive Care St. Petersburg, Russian Federation

Full list of author information is available at the end of the article patients received Clonidine $1-2,63 \mathrm{mkg} / \mathrm{kg}$, in the 2 -nd group (42) - Dexmedetomidin 0,88-2,33 $\mathrm{mkg} / \mathrm{kg}$.

Monitoring of the main hemodynamic indicators (systolic/ diastolic blood pressure, heart rate) was carried out by the device "Nihon Kohden". All operations were performed under control of the sedation depth by the device "BIS Aspect".

\section{Results}

In the 1-st group all the patients (21) demonstrated the reduction of the heart rate after introduction of the anesthesia by $7,7-50 \%$ from a reference value. In 1 case $(4,8 \%)$ the increase of systolic AP (arterial pressure) for $11,5 \%$ and the diastolic AP for $31,2 \%$ of reference value was noted. In other 20 cases $(95,2 \%)$ there was a decrease of systolic AP for 7,1 - 48,1\% and the diastolic AP for $12,5-55 \%$. In the2-nd group all 42 patients demonstrated the decrease of the heart rate by $18,2-61,5 \%$ after the introduction of anesthesia. In 34 cases $(80,9 \%)$ the increase of systolic AP for $0-58,3 \%$ (average value 21 $\pm 12,7 \%)$ and the diastolic AP for $0-57,1 \%$ from reference values was noted. In other 8 cases $(19,1 \%)$ there was a decrease of systolic AP for 16,1 - 36,7\% and diastolic AP for $10-38,1 \%$.

In all 63 cases these changes were observed in the conditions of the sufficient depth of sedation by BIS (15-30).

\section{Conclusions}

Thus, when using Clonidine for neurovegetative stabilization, in $95,2 \%$ of cases the central simpatolytic effect causing decrease in heart rate and AP prevailed. And in cases with Dexmedetomidin's application in $80,9 \%$ of 
patients after an introduction anesthesia the peripheral vasoconstrictive effect, causing the increase of system vascular resistance and AP with further decrease in heart rate, prevailed.

\section{Authors' details}

${ }^{1}$ Federal State Institution 'North-West Federal Research Center' of the Russian Ministry of Health, Anesthesiology and Intensive Care St. Petersburg, Russian Federation. ${ }^{2}$ Federal State Institution 'North-West Federal Research Center' of the Russian Ministry of Health, St. Petersburg, Russian Federation.

Published: 1 October 2015

doi:10.1186/2197-425X-3-S1-A988

Cite this article as: Nazarov et al: Comparison of clonidine and dexmedetomidin influence on the main indicators of hemodynamic during induction of anesthesia in neurooncological patients. Intensive Care Medicine Experimental 2015 3(Suppl 1):A988.

\section{Submit your manuscript to a SpringerOpen ${ }^{\mathcal{O}}$ journal and benefit from:}

- Convenient online submission

- Rigorous peer review

- Immediate publication on acceptance

- Open access: articles freely available online

- High visibility within the field

- Retaining the copyright to your article 